\title{
The Role of Motivation in Learning Chinese as a Second Language: A Case study of Zimbabwean Students Learning Chinese as a Second Language
}

\author{
Faith Mkize $^{1}$, Godfrey Chisoni \\ ${ }^{1}$ Department of Modern Languages; Faculty of Arts, University of Zimbabwe, Harare, Zimbabwe \\ ${ }^{2}$ Department of Linguistics and Applied Linguistics, Faculty of Arts, Jilin University, Changchun, China
}

Email address:

faizomki@gmail.com (F. Mkize), gchisoni@yahoo.com (G. Chisoni)

\section{To cite this article:}

Faith Mkize, Godfrey Chisoni. The Role of Motivation in Learning Chinese as a Second Language: A Case study of Zimbabwean Students Learning Chinese as a Second Language. International Journal of Language and Linguistics. Vol. 3, No. 4, 2015, pp. $252-257$.

doi: $10.11648 /$ j.ijl1.20150304.19

\begin{abstract}
Motivation in second language learning is an important factor that should be never ignored, it requires much attention for second language learning and teaching to be successful, the students should be motivated and the teacher needs to employ teaching methods that motivate the students in acquiring their target language. This research was conducted at the University of Zimbabwe Confucius Institute which is the main center for teaching and learning of Chinese language and culture in Zimbabwe and concluded that students who are motivated are easy to teach and can perform better without much assistance from the instructor. The paper discusses the role played by motivation in the acquiring of second language, which is Chinese language, and the impact it has in improving the target language by students. Usually the teaching methods and criteria used by the teachers to reward or motivate the students are the ones which determine the students' performance in the second language learning. Without motivation students easily quit or lose interest in the target language. However, although motivation plays a pivotal and unreplaceable role in the second language learning and teaching, it is easily forgotten and not given much attention. This paper will also focus on showing the impact motivation has in the second language learning and teaching, and how the University of Zimbabwe students are being motivated to acquire Chinese as a second language. Most teachers know and are aware of the importance of motivation in second language learning, but easily neglected in the actual teaching and learning process. Motivation provides the primary impetus to initiate learning the L2 and the driving force to sustain the long and often tedious learning process. The University of Zimbabwe students who are learning Chinese are motivated well but there is still need for review of the teaching methods and the frameworks being used, since the majority of the students complained about the methods used in class.
\end{abstract}

Keywords: Motivation, Second Language Learning, Chinese as a Second Language, Confucius Institute

\section{Introduction}

In the recent years China's economy has been growing so fast, this has come as a result of the expansion and increase in trade by Chinese companies with other countries of the world. The influence of China on the contemporary international affairs has also increased the need for people from all over the world to study Chinese language in order to meet the socio-political and economic demands. According to Liu Xun (2013:4) Chinese language is now one of the six languages used at the United Nations. In this contemporary period learning Chinese language has become a necessity all over the world. The number of people learning Chinese language is increasing very fast, according to a recent report from the Xinhua News Agency, there are currently "more than 100 million foreign speakers and learners of Mandarin worldwide with 350,000 foreigners studying Chinese language in 746 Chinese universities last year." (14/July/2014).

The increase in people learning Chinese can also be attributed to the tremendous efforts by the Chinese government in the promotion of the Chinese language and culture. The government of China has set up a national office which is responsible for the spreading and promotion of Chinese language. Chinese language is promoted through the National Office for Teaching Chinese as a Foreign Language 
(NOCFL), it's also known as Hanban1 in Chinese language. According to its website: "Hanban is committed to making Chinese language and culture teaching resources and services available to the world, to meeting the demands of overseas Chinese learners to the utmost, to contributing to the formation of a world of cultural diversity and harmony". (Hanban website)

The Chinese government through Hanban has helped to establish Confucius Institutes all over the world which is responsible for the promotion and spreading of Chinese language and culture. Confucius Institutes are a network of non-profit public institutions affiliated with the Chinese Ministry of Education. They are designed to support the growth of Chinese language and culture worldwide, as well as the training of Chinese teachers. They are administered by the Chinese National Office for Teaching Chinese as a Foreign Language, a non-government agency reporting directly to the Ministry of Education.

The first Confucius Institute opened in 2004. By mid-2013, over 300 Confucius Institutes had been established in 93 countries and regions, and the network is expanding rapidly toward a reported goal of 1,000 centers by 2020 (People's daily Online 14/10/14). The drive for people to learn Chinese language differs from country to country ,from school to school and also to individuals. The drive or the factor that stimulates or makes people want to learn Chinese language which can be called motivation is also one of the factors that can influence the rate at which people acquire the language and want to learn it. In the UK for instance according to British Education Minister Elizabeth Truss:

"China's growing economy brings huge business opportunities for Britain, and it is vital that more of our young people can speak Mandarin to be able to trade in a global market and to develop successful companies.'(People's Daily China: 14/10/14) Most employers now are demanding that college graduates should be fluent in one foreign language, and Chinese is one of the few languages on high demand.

China and Africa have been enjoying good bilateral relations for a long-time. According to Bergsten et al.,(2006:129), from the 1950s to the late 1970s, China's foreign policy was focused on encouraging and supporting revolution in other parts of the world ,particularly Southeast Asia and Latin America, and this shifted after China's opening up reform led by Deng Xiaoping in 1978. Entering the $21^{\text {st }}$ century China's relationship with Africa was strengthened, were China was no longer only providing political support but also considerable economic opportunities, and trade. In the year 2000 China created FOCAC2 (Forum on China-Africa Co-operation) which was

1 HANBAN is the colloquial abbreviation for the Chinese National Office for Teaching Chinese as Foreign Language .It is governed by the Office of Chinese Language Council International, a non-government and non-profit organization affiliated with the Ministry of Education of the People's Republic of China. http://www.ask.com/wiki/Hanban.

2 FOCAC (Forum on China-Africa Co-operation is an official forum between the People's Republic of China and the states of Africa. http//:africanews.com aimed at cementing and expanding the political and economic ties with African countries. This development saw the rise in business opportunities and business people from Africa learning Chinese language and employers interested in employing people who are competent in Chinese language. The spread of Chinese language in Africa has been very fast, Egypt has the highest number of students studying Chinese out of all African countries, and Zimbabwe has made a remarkable development in the teaching and learning of Chinese now having the highest number of local people who are qualified to teach Chinese language and culture (People's Daily Online, 14/10/14).

The Zimbabwean government led by President R.G Mugabe introduced the "Look East Policy 3 ". With the introduction of "Look East Policy" by the Zimbabwean government the teaching and learning of Chinese language became a necessity as a way of bridging the gap between China and Zimbabwe. The University Of Zimbabwe Faculty Of Arts teaches four foreign languages: German, Chinese, French and Portuguese. In August 2006 the University of Zimbabwe signed a memorandum of agreement with the Renmin University of Chin, that the two Universities would work together in the teaching and learning Chinese at the University of Zimbabwe Confucius Institute, in the agreement, Renmin University of China would provide support through sending voluntary teachers to teach Chinese language and culture amongst other things. The agreement was made through the support of Confucius Institute headquarters (Hanban) in Beijing for the teaching and learning of Chinese language, and a Confucius institute was established at the University of Zimbabwe. Chinese language is thereby being taught not only to students of the University of Zimbabwe but also offered to anyone who wants to learn the language and culture of the Chinese people.

For second language learning and teaching to develop and to be successful there should be something that inspires, incites or stimulates a person to and in learning the second language, which in other words is called motivation. The term "motivation" is a broad word in which no scholar has been able to define it fully, and different scholars have different perceptions on the term motivation. Gardner (1985) defines motivation as a combination of effort plus desire to achieve a goal plus favorable attitudes towards the goal to be accomplished. However at a presentation at the Seminario Sobre Plurilingüismo: Las Aportaciones Del Centro Europeo de Lenguas Modernas de Graz, on December 15, 2006 at the Universidad de Alcalá, Spain4. Gardner acknowledges that the term "motivation" can be listed into characteristics of a motivated person and these include: goal directed, self-

\footnotetext{
3 Look East policy. Zimbabwe's Look East policy, is aimed at promoting and cementing bilateral relationship with East Asian countries like China, Singapore, Malaysia, Japan, promoting business and trade, especially with China promoting economic trade and more business opportunities between the two countries. www.ask.com/zimbaweanlookeastpolicy .

4 Translated from Spanish to English: The Seminar Multilingualism: The Contributions from the European Centre for Modern Languages in Graz, on December 15, 2006 at the University of Alcalá, Spain. (Google translate)
} 
confidence, persistent. Motivated learners are every teacher's dream-they are willing to work hard, add their own goals to those of the classroom, focus their attention on the tasks at hand, persevere through challenges, do not need continuous encouragement, and may even stimulate others in the classroom, promoting collaborative learning. In second language learning most people neglect or forget the role played by motivation, some teachers have no knowledge of the role played by motivation and how these roles can affect a student's behavior and attitude towards the language. According to Gardner (1985) there are two types of motivation, which is language learning motivation and classroom learning motivation, all these types of motivation are so important to the growth and development of second language learning. Motivation according to Winnie and Marx (1989), is a crucial factor for success in second language learning, it is a both a condition for, and a result of, effective learning. Motivation is very important in every second language, but most researchers and language teachers usually forget the importance of motivation in second language learning, motivation has been called the "neglected heart" of language teaching (Abbas Pourhosein Gilakjani: 2012).

This paper seeks to look at Chinese language learners' motivation in learning Chinese language; the paper will attain its information by researching on Zimbabwean students learning Chinese language, to see if the teachers are aware about the role played by students' motivation in second language learning, to see what are the motivating factors in the learning of Chinese language in Zimbabwe, to see if students are being motivated enough and to see what is the role of motivation in the learning and development of Chinese as a second and foreign language. Is the motivation adequate, is there something that needs to be done to raise awareness of the importance of motivation in learning of Chinese language, what are the methods and ways used to motivate the students to learn Chinese language faster and finally to suggest solutions to the problems discovered by the research on the students' motivation in learning Chinese language.

\section{Background}

The learning of Chinese language by foreigners can date back to $16^{\text {th }}$ Century when some European missionaries used to come and preach the gospel in China and at the same time they would learn some basic Chinese language and culture (Liu Xun 2002). In Africa, during the same period, the $16^{\text {th }}$ Century, some Chinese business people would go to some African countries where they used to do business with the African locals of that time, and they would learn Chinese language for better communication. (Manyeruke C \& L Mhandara, 2011:87)

After the Republic of China was formed in 1949, the following years saw the rise in foreigners learning Chinese language. By the beginning of the $21^{\text {st }}$ the learning of Chinese language grew very fast with the number growing up to 40 million in 2006 and almost 100 million in 2010
(People's Daily Online). A number of factors have contributed to the fast development of learning Chinese the world over. In Zimbabwe for example the introduction of the FOCAC in the year 2000 which boosted the already existent friendship between African countries and China, also influenced many African people to study Chinese language and culture as most African were engaging with Chinese people in doing business. Also in 2003 due to Zimbabwe's economic situation which was crumbling down due to the targeted sanctions which were imposed by the western countries, Zimbabwe introduced the 'look east policy'. In terms of this policy Zimbabwe prioritized its relationships with countries such as China, Singapore, Iran, Indonesia, India and Malaysia. The introduction of the 'look east policy' lead most Zimbabweans also to learn Chinese language as China was now involved in many things (Zhang Chun 2014). In the year 2007 Zimbabwe introduced Chinese language and culture courses formally at the University of Zimbabwe, where a Confucius Institute was established. According to the Xinhua News Agency at first, only 30 students enrolled to learn Chinese language at that time and the number has risen so fast with the year 2013 recorded more than 3000 students have been enrolled and have studied Chinese language at the University of Zimbabwe .

Although the learning and teaching of Chinese has developed so fast in Zimbabwe, studying Chinese language is still considered very hard. A lot of students after enrolling to study Chinese language end up quitting, and very few students have successfully mastered the language to the extent of being able to use it. Some students have studied Chinese for more than two years at the University of Zimbabwe Confucius Institute for a maximum of 6 months and have already mastered the basics and some have been studying for more than 2 years and still cannot even say the most basics. The reason for the differences in what motivates other students over other students it's still not clear as no research about it has been done. This paper seeks to explore to what extent students are motivated by the society they live to learn Chinese and how they are also motivated in class and the school to study Chinese language. Are the teachers at the Confucius Institute at the University of Zimbabwe aware of the importance of motivation in class room teaching? How and what methods are being used by the teachers to motivate students to learn Chinese? If the students are not motivated enough, what steps are being taken or what measures are used by the teachers and the school to ensure that every student is motivated enough to study Chinese language. The paper will also study the extent to which motivation plays a role in boosting the student's acquisition of the second language.

\section{Brief Literature Review}

Motivation in second language is not a new subject; it has been widely accepted by both teachers and researchers as one of the factors that affect the rate and success of second /foreign language learning. Zoltan Dorbyei (1998:117) argues 
that motivation provides the primary impetus to initiate learning the L2 and later the driving force to sustain the long and often tedious learning process; indeed, all factors involved in L2 acquisition presuppose motivation to some extent.

A considerable amount of research has been done on the influence of motivation on the acquisition and learning of second/foreign languages. Gardner and his colleagues pioneered the researches on the influences of motivation and its effects on the second language acquisition. In their researches Gardner and his colleagues agreed that, without sufficient motivation, even individuals with remarkable abilities cannot accomplish long-term goals .Abbas Pourhosein Gilakjani (2012) et al: argues that, motivation is a combination of effort plus desire to achieve a goal plus favorable attitudes towards the goal to be accomplished, and motivated learners are every teacher's dream, they are willing to work hard, add their own goals to those of the classroom, focus their attention on the task at hand, persevere trough challenges, and they do not need continuous encouragement.

However although many scholars have been talking about the positive outcomes that comes from motivated students, some scholars have brought out some negative outcomes that might be brought by motivation in second language learning, Gardner and Lambert (1972) emphasize that, although language accounts for a considerable proportion of individual variability in language learning achievement, motivational factors can override the aptitude effect, they also pointed out that in certain language environments, where the social setting demands it ( e.g. when the L1 is a local vernacular and the L2 is the national language), many people seem to master an L2 ,regardless of their aptitude differences. The teaching and learning of Chinese language is a new phenomenon which hasn't got much researches on it. Many researches have been done, but scholars have been focusing more on other issues for example the difficultness of learning Chinese characters, the complicatedness of Chinese grammar over many other issues and researches on the influences of motivation on the acquisition of Chinese language are very limited. The few researches that have been there on the influence of motivation, also didn't focus on countries like Zimbabwe where Chinese language is a completely new subject, in a new learning environment and with new teaching strategies and methods. This paper will focus on the role that motivation plays in the teaching and acquisition of Chinese language in Zimbabwe. Zimbabwe's language background is completely different from other American or European countries and as a third world country, the factors that motivate students to learn a certain language are different ,hence this papers wants to find out how are Zimbabwean students are motivated in the learning of Chinese language and culture.

\section{Research Questions and Aims}

Motivation has a very big role in second language learning, for students to effectively acquire second language and for second language to happen there is need for some motivating factor for students to quickly acquire the language and reach there goals. The purposes of this research are:

- Equipping the instructor/teacher with knowledge on what motives students to learn Chinese language.

- Analyze the motive behind the influx in number if students wanting to learn Chinese, and how these motivating factors have contributed to the rise in teaching Chinese in general.

- Find out if motivation is playing a role in the teaching and learning of Chinese language at the University of Zimbabwe and to the Zimbabwean students learning Chinese.

- Equip the instructor with ways on how to motivate a student, and to find new frameworks and methods that can be used to empower and motivate students in acquiring Chinese as a second language

- The research also aims at showing:

- Motive behind university of Zimbabwe students learning Chinese

- What and how teachers are doing to motive the students

- Importance of motivation in second language learning.

- Ways in which one can motivate a student and cause them to also be self-motivated.

\section{Research Methodology}

Through qualitative research methods this paper aims at analyzing the different reasons behind ones motive in learning Chinese language at the University of Zimbabwe. The research will be done using questionnaires. Although the questions on the questionnaires will be the same in analyzing we shall group them into 3 groups according to R.C.Gardner's stages of acquiring a second language.

Elemental; this stage will be focusing on the first year students. First year students are those who have been learning Chinese from 0-12 months. These are individuals who are learning the basics of the language, vocabulary, grammar and pronunciation. W.E Lambert (1955) calls this the vocabulary cluster

Consolidation; this stage will focus on the second Year students. These would have been learning Chinese language from 1-2 years. These individuals will be learning the elements of the language brought together. Develop rules for pluralization, sentence structure

Conscious expressions; this stage will focus on the third year students. These individuals will be using the language to communicate with a great deal of consciousness. They will be able to communicate their ideas and thoughts using Chinese language.

\section{Data Analysis}

The research was done through questionnaires at the University of Zimbabwe Confucius Institute, which is the main center of learning Chinese language and culture in Zimbabwe. A total of 60 students participated in the research 
and four teachers who are teaching the students also participated through a different questionnaire.

From the students who participated in the research, 20 of the students are still in the elementary class. These are those students who have studied Chinese for less than 12 months and are just acquiring the basic Chinese language and culture. The other group had also 20 students who participated in the research, these are those students who have already studied Chinese language for 12 to 24 months, and the last group of 20 students are those who have already mastered a considerable amount of vocabulary and can already communicate the basic Chinese without much problems.

Although the Zimbabwean students who are learning Chinese are in different stages, there responses as to what motivates them in studying Chinese language did not differ very much from each other. The first question from the questionnaire asked, where and when do students learn better and think they acquire more Chinese language, majority of the students said they learn better when they are at school, thus during classes when they are with teachers and they are directed in class. This question was directed at understanding how the students learn Chinese and to see if they are motivated to study the Chinese even at their spare time. However, a considerable number of about 21 students out of the 60 students that participated said they also study at home, thus they study both at home and school. Some of the students, thus 5 of the students who participated in the research said they also study with friends, during break time and whenever they meet they prefer to communicate in Chinese so that they can improve their Chinese .

The other question which was targeted at the students asked about what motivated them to learn and what demotivates them in learning Chinese as a second languages. The majority of the students said that they are motivated by the fact that after they learn Chinese and they can speak it well they can acquire a stable and good job, thus most students are learning Chinese in Zimbabwe so that after they master it they can be employed in Chinese related companies where they can be language translators or interpreters since Chinese companies are expanding very fast and those who can speak Chinese companies don't struggle very much to secure employment. Some of them said that they are motivated by the people who have already mastered the language and are already employed, they argued that if you compare their lives are better than most people citing an example of some Chinese local teachers at the University of Zimbabwe Confucius, who are securely employed and can speak good Chinese.

Other students gave various reasons, and what motivates them in learning Chinese. A group of the students said they are motivated to learn Chinese because they would like to pursue further studies in China, and some just because they are interested in Chinese language and culture.

More than half of the students who participated in the research said there are a number of things that demotivates them in learning Chinese. They argued that, they are mainly demotivated or discouraged during class time as they say some of the teachers favor other students over others which affects others negatively, and they end up losing interest in the target language. These group of students argued that the teacher usually favors those students who perform better in the class and ended up neglecting other students and this will affect them psychologically and thereby ending up producing bad results. Other students also say the methods that are used to teach them are not quite good or they are not very familiar with them which will make them lose passion about the subject being taught, for example they said other teachers will force them to form sentences after they just learnt the new words, and they say this is embarrass them and also make them lose interest in the subject. However this is different to students who have already learnt Chinese for more than 2 years, this group said they are not discouraged by failure to form sentences in class as this is a challenge to them which makes them working hard and encourages them to preview their classes.

Another question asked on how and what other methods and sources they use to learn Chinese. From the first level to the third level all agreed that they use internet to study, which they say they use social media to chat with Chinese language native speakers, use electronic and online dictionaries for referencing and other online sources to boost their Chinese language. Television programs also motivates students as they can see native speakers of the target language, also they will be having the audiovisual assistance, the internet keeps them aware of the things happening around the world and motivates them to learn more harder to be like other students around the world. Another group of students said they are encouraged in their communities and family as China and Zimbabwe share a good relationship and to speak Chinese language is seen as a valued resource for the strengtheni9ng of the relationship.

The other questionnaire was targeted to the teachers. All the ten teachers available responded to the questions very well. Most teachers said they motivate their students through various games in class, this they say it allows even those very quiet or shy students to participate in class. At the University of Zimbabwe they also help students who pass certain levels of Chinese Proficiency Test to get scholarships to go and study in China, either for short periods like the International Summer School which usually runs for one month or sometimes they are helped to get scholarships for six months, one year or even three years. This, they say has increased completion in the classes and has boosted the results.

\section{Suggestions and Conclusion}

\subsection{The Importance of Motivation}

As Marx (1989), suggests that motivation in second language is a condition for and a result of effective instruction. In the discussion we have seen how the University of Zimbabwe Chinese students are motivated and also demotivated in the learning of Chinese language process. Motivated students are every teachers dream as they are not 
forced to learn but they can by themselves do wonderful things in class room and out of the classes. They don't need constant reminder of the importance of working harder to achieve their goals and they can find their own learning strategies which can help them to master the first language without the teachers help always.

\subsection{How and what Second Language Teachers and Students Should Do to Motivate Students}

This paper cannot tackle all the problems mentioned in the researches, but can suggest that the language teachers need to understand there students, and find new teaching frameworks which encourages every student in the class, and boost the results. A majority of the students complained that some of their teachers demotivates them through the teaching methods they use and through favoritism, it is important for the teachers to understand their students and to take their students as equal. Each student should be given as much attention during lectures as the other. In the analysis it is shown that most students learn Chinese language at the University. This shows the role of the environment in the learning of Chinese language. Hence if possible the teachers should try and create an environment that is conducive for students to have their group discussion, play audio tapes or watch $\mathrm{CD}$ during their spare time. Secondly the Confucius Institute needs to create more links with Chinese companies to enable students to go work there after graduating. A few links have been however been created to offer the best students jobs but due to the great number of Chinese students they is still need for more to be done.

According to Abbas Pourhosein Gilakjani et al (2012), Motivation has been called the "neglected heart" of language teaching...as teachers often forget that all the learning activities are filtered through students motivation. When there is no motivation there is no life in class. In as much as the students are motivated, it is important that teachers understand their students and know what time of motivation they would need.

\section{References}

[1] Abbas Pourhosein Gilakjani, Lai-Mei Leong \&Narjes Banou Sabouri(2012), A study on the Role of Motivation in Foreign Language Learning and Teaching. 2012.07.02

[2] Dörnyei, Z. (1998, March).What is motivation? Paper presented attheAAAL1998 Conference, Seattle, WA.

[3] Dörnyei, Z \& Otto, I. (1998). "Motivation in action: A process model of L2 motivation". Working Papers in Applied Linguistics, 4: 43-69

[4] Dörnyei, Z. and Schmidt, R. (Eds.), Motivation and Second Language Acquisition (pp. 1-20). Honolulu, HI: University of Hawai'i Press.

[5] Gardner, J. (2001). Integrative Motivation and SecondLanguage Acquisition. In Dörnyei, Z. and Schmidt, R. (Eds.), Motivation and Second Language Acquisition (pp. 1-20). Honolulu, HI: University of Hawai'i Press.

[6] Gardner, R. and Lambert, W. (1972). Attitudes and Motivation in Second-Language Learning. Rowley, MA: Newbury House.

[7] Gardner, R. and Lambert, W. (1972). Attitudes and Motivation in Second-Language Learning. Rowley, MA: Newbury House.

[8] Liu Xun (2013:4). Chinese as a Second Language .Beijing Language and culture University Press. 2013.

[9] The People's Daily (2006) Wanted: Four million Chinese teachers for students. Availableathttp://english.peopledaily.com.cn/200605/23eng20 060523 267727.html<accessd on 28/11/14>

[10] Xinhua News Agency (14/July/2014). Teaching and learning of Chinese as a foreign language conference. Dörnyei

[11] Zhang Chun (2014), China-Zimbabwe Relations: A Model of China- Africa Relations Volume 205 